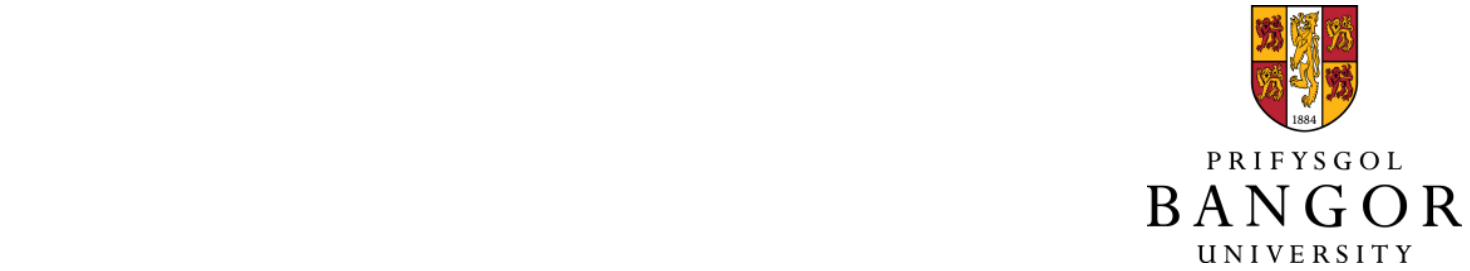

Assessment of the use of dynamic mechanical analysis to investigate initial onset of brown rot decay of Scots pine (Pinus sylvestris L.)

Ormondroyd, Graham; Alfredsen, Gry; Raghavalu Thirumalai, Durai; Curling, Simon; Stefanowski, Bronia; Spear, Morwenna; Gobakken, Lone Ross

\title{
International Biodeterioration and Biodegradation
}

DOI:

10.1016/j.ibiod.2017.02.002

Published: 01/05/2017

Peer reviewed version

Cyswllt i'r cyhoeddiad / Link to publication

Dyfyniad o'r fersiwn a gyhoeddwyd / Citation for published version (APA):

Ormondroyd, G., Alfredsen, G., Raghavalu Thirumalai, D., Curling, S., Stefanowski, B., Spear, M., \& Gobakken, L. R. (2017). Assessment of the use of dynamic mechanical analysis to investigate initial onset of brown rot decay of Scots pine (Pinus sylvestris L.). International Biodeterioration and Biodegradation, 120, 1-5. https://doi.org/10.1016/j.ibiod.2017.02.002

\footnotetext{
Hawliau Cyffredinol / General rights

Copyright and moral rights for the publications made accessible in the public portal are retained by the authors and/or other copyright owners and it is a condition of accessing publications that users recognise and abide by the legal requirements associated with these rights. study or research.

- Users may download and print one copy of any publication from the public portal for the purpose of private

- You may not further distribute the material or use it for any profit-making activity or commercial gain

- You may freely distribute the URL identifying the publication in the public portal?
}

Take down policy

If you believe that this document breaches copyright please contact us providing details, and we will remove access to the work immediately and investigate your claim. 


\section{Assessment of the use of dynamic mechanical analysis to investigate}

2 initial onset of brown rot decay of Scots pine (Pinus sylvestris $L$.)

Ormondroyd, G.A. ${ }^{1,3 ; *}$ Alfredsen, G. ${ }^{2}$ Durai Prabhakaran, R.T. ${ }^{1}$ Curling, S.F. ${ }^{1}$ Stefanowski, B.K. ${ }^{1}$ Spear M.J. ${ }^{1}$ Gobakken, L.R. ${ }^{2}$

1 The BioComposites Centre, Bangor University, Gwynedd, LL57 2UW UK

2 Norwegian Institute of Bioeconomy Research, Box 115, NO-1431 Ås, Norway

${ }^{3}$ Department of Architecture and Civil Engineering, University of Bath, Bath, UK

* Corresponding author. Tel. +44 (0)1248 383898 E-mail address:

g.ormondroy@bangor.ac.uk (G.A. Ormondroyd)

\section{Abstract}

Microbiological degradation of wood by decay fungi can cause a rapid change in the structural properties of timber which can result in both strength and mass loss. Traditional techniques for the evaluation of decay (e.g. mass loss) lack the sensitivity to evaluate the effects of the very first stages of the decay process. This paper describes the effects of initial brown rot decay, defined by the amount of Poria placenta genomic DNA (gDNA) present in the samples, on the dynamic mechanical properties of the timber. It was found that there is a correlation between the mean storage modulus of the timber and the amount of P. placenta gDNA present, and therefore the level of decay. This shows that using dynamic mechanical analysis is a viable technique that can be used to study initial decay processes.

Keywords: decay, Poria placenta, viscoelastic behaviour, dynamic mechanical analysis (DMA),

\section{Introduction}

Microbiological degradation of wood by fungi can cause a rapid change in the structural properties of timber (Jellison et al., 2013), however traditional techniques for the evaluation of the decay (e.g. mass loss) lack the sensitivity to evaluate the effects of decay in the very first stages of the decay process.

The mechanism for the decay of timber via brown rot is through oxidative and enzymatic reactions (Goodell et al., 1997; Arantes et al., 2012; Alfredsen et al., 2015, Zelinka, 2016). The fungus initiates the production of hydroxyl radicals by secreting hydrogen peroxide and reductants in to the cell wall. The reductants reduce the ferric iron $\left(\mathrm{Fe}^{3+}\right)$ to ferrous iron $\left(\mathrm{Fe}^{2+}\right)$ (Goodell et al., 1997; 2006), which then reacts with the hydrogen peroxide to form hydroxyl radicals in the Fenton reaction. The hydroxyl radicals depolymerize hemicelluloses and cellulose, modify lignin and generate sufficient rearrangements in the cell wall to allow the hydrolysing enzymes to diffuse in to the wall and degrade the polysaccharides (Goodell et al., 1997; Baldrian and Valaskova, 2008; Arantes et al., 2012). Ray et al. (2010) terms the above mechanism the Early Stage Decay Mechanism (ESDM) and suggest that it can act both rapidly and extensively. This mechanism has also been referred to as chelator-mediated Fenton 

both noted that whilst the reduction in the degree of polymerization is rapid there is low mass loss at this stage of decay. The study of early onset decay has, in recent years, been furthered by the use of molecular techniques. gDNA quantification has shown to be more sensitive than ergosterol and kition assays for estimation of fungal biomass in early stages of decay both in sterile laboratory samples (Eikenes et al. 2005) and for field samples (Pilgård et al. 2011). Hietala et al. (2014) found that the suppressive effect of suboptimal temperature on wood decay caused by P. placenta appeared more pronounced in Scots pine heart wood than in sapwood. At $30^{\circ} \mathrm{C}$ heartwood showed no mass loss, poor substrate colonization (gDNA quantification) and marker gene transcript level profiles indicating a starvation situation.

Alfredsen et al. (2015) reviewed the role of quantitative gDNA and gene expression studies in the understanding of the mode of action of brown rot decay on modified wood, charting the method development and recent studies. Based on gene profiles the studies provide indications of a possible shift toward increased expression, or at least no down regulation, of genes related to oxidative metabolism and no reduction, or concomitant reduction, of genes related to the enzymatic breakdown of polysaccharides in modified wood compared to untreated control. Using gene expression Ringman et al. (2014) showed that P. placenta was present in acetylated, DMDHEU-treated and thermally modified wood after 2 days while at 6 days, the gene expression levels were significantly different from zero. Alfredsen et al. (2016) found P. placenta gDNA in acetylated samples with high treatment level (22\% acetyl content) after four weeks while initial mass loss was not detected until 20 weeks. It is interesting to note that the time to mass loss of the acetylated timber was in agreement with other researchers (Hill et al., 2006). However, fungus was present in the timber much earlier in the test, which suggests a good efficiency of acetylation in the prevention of decay.

Compositional data and structural properties of wood have also been used in investigating the early stages of brown rot decay. Monrroy et al. (2011) assessed the change in the degree of polymerization of the cellulose (of Pinus radiata), the crystalline structure of the cellulose and the hemicellulose content of the wood over a decay period of 8 weeks (using $20 \mathrm{~mm} \times 25 \mathrm{~mm} \times 5 \mathrm{~mm}$ chips). Different species of brown rot were assessed with Gloeophyllum trabeum showing the highest rate of cellulose degree of polymerisation reduction and Laetiporus sulphureus showing a comparable loss in cellulose crystallinity. Curling et al. (2002) examined the effect on the hemicellulose content and the mechanical properties of southern yellow pine exposed to brown rot fungi. Their data showed that during initial decay, where there was negligible weight loss (up to 20 days exposure), there were significant changes in hemicellulose content associated with up to a $20 \%$ loss in modulus of elasticity, $40 \%$ loss in modulus of rupture (4 point bending strength) and $80 \%$ loss in work to maximum load. This indicates that physical properties may be a more appropriate method of studying early stage decay than simple mass loss. Their method used static mechanical tests to derive the data, although there is another physical characterisation method, Dynamic Mechanical Analysis (DMA), which has become a well-established technique for dynamically measuring the viscoelastic behaviour of polymers and polymer composites. The earliest examples of DMA studies on wood were in the 1960s using torsional pendulum apparatus (Norimoto and Yamada, 1966; Becker and Noack, 1968). DMA is often used to measure the response of a material to changes at the molecular or microstructural level (often but not always brought on by a change in temperature). In 
their paper, Birkinshaw et al. (1986) assess the response of 10 timber species to dynamic flexing whilst being subjected to a temperature gradient raising from $10{ }^{\circ} \mathrm{C}$ to $100{ }^{\circ} \mathrm{C}$ at $10{ }^{\circ} \mathrm{C} \mathrm{h}^{-1}$. The species were selected for their variety in densities and in microstructure. It was noted that whilst the absolute values had a large variation the general shape of the shear storage modulus curve and the loss modulus $(\tan \delta)$ were similar. Much research has been undertaken to determine the response to changes in both temperature and humidity; the effect of the humidity and moisture content of the wood on the glass transition temperature $\left(\mathrm{T}_{\mathrm{g}}\right)$ and other relaxations of the lignin and hemicelluloses of wood; and the effect on the mechanical properties of the timber (Hillis and Rossa, 1978, 1985; Kelley et al., 1987; Salmén and Olsson, 1998; Olsson and Salmén 2004).

An important factor in the use of DMA is the determination of the Linear Viscoelastic Response region (LVR), and experiments should be conducted within this region. Within this region the strain is directly proportional to the stress and therefore the polymer packing is not altered by the stress applied; however, once the response becomes nonlinear the polymer packing is being significantly and irreversibly altered. Sun et al. (2007) used DMA to assess the dynamic response of timber at low moisture content $(<1 \%)$; they noted that the LVR was very low, between $0.03 \%$ and $0.16 \%$ strain although values were greater when bending perpendicular to the grain.

McCarthy et al. (1991) studied the fungal degradation of wood via DMA. Small samples were exposed to the brown rot fungus Coniophora puteana over a six week period on a weekly basis in accordance with ASTM D2017 and DIN 50 008. The response to dynamic loading was measured between $-100{ }^{\circ} \mathrm{C}$ and $250{ }^{\circ} \mathrm{C}$ at a heating rate of $5{ }^{\circ} \mathrm{C} \mathrm{min}-1$. The researchers showed that the shear modulus fell with increased amounts of decay at all temperatures. It was noticed that whilst the absolute values for the modulus changed with the increase in decay, $\tan \delta$ and the shape of the shear modulus curve did not change significantly. It should be noted that this is in agreement with the earlier work of Birkinshaw et al. (1986), in that there are changes in the absolute values but not the location of the $\tan \delta$ peak. Whilst we understand that the oxidative reaction depolymerizes the wood holocelluloses prior to the components being utilized by the fungi (which does not lead to a mass loss), the implication of this research is that the ultimate degradation of the polymers responsible for the stiffness of the wood is relatively uniform in rate.

The investigations undertaken to date have focused on the assessment of wood's ability to respond to a dynamic temperature range and the effects of altering the molecular and microstructure of the wood. The objective of this study was however, to determine the potential of DMA, under isothermal conditions, as a method for the assessment and quantification of initial onset brown rot decay.

\section{Materials and methods}

Scots pine (Pinus sylvestris L.) from South Norway was supplied by Norwegian Institute of Bioeconomy Research Norway. The pine was straight grained and had an average growth ring distribution of 10 rings/cm. The Scots pine was then machined to $2 \mathrm{~mm} \times 2$ $\mathrm{mm}$ strips and samples were selected to achieve 1 single latewood band through the centre of the strip. All samples were conditioned to $65 \% \mathrm{RH}$ at $20^{\circ} \mathrm{C}$ before testing. 

(originally from the European recognized holding lab as defined in EN 113) were grown on $90 \mathrm{~mm}$ Petri dishes containing 4\% malt agar (Malt extract powder $40 \mathrm{~g}$; Agar $20 \mathrm{~g}$; Deionised water 1 litre). P.placenta (FPRL 280) is a fungal isolate stipulated by a number of European testing standards for example EN113 (CEN 2004). Once the fungal culture had grown to cover the entire surface of the plate the cultures were ready for samples. Wood samples ( $2 \mathrm{~mm} \times 2 \mathrm{~mm} \times 80 \mathrm{~mm}$ ) were cleaned by immersing them in ethanol for 1 minute. The samples were then dried and vented aseptically using a laminar flow bench. Once dry, the samples were aseptically placed onto the pre-prepared fungal cultures as follows: two samples were placed in direct contact with the agar/fungus to act as supports, with three further samples placed perpendicular and on top of the supports. This was intended to prevent water logging which may have prevented decay. The cultures were then incubated at $22{ }^{\circ} \mathrm{C} \pm 2$ at $70 \% \mathrm{RH} \pm 3$ with replicate samples $(n=6)$ removed (aseptically) from incubation after 4, 8, 11 and 17 days. Upon removal from test the wood samples were dried for $12 \mathrm{hrs}$ at $50{ }^{\circ} \mathrm{C}$ in order to stop fungal growth without degrading any DNA. Dried samples were stored in sterile tubes before subsequent DNA isolation and testing.

\subsection{Assessment of the decay}

As weight loss is not an accurate measure of the early onset of brown rot decay, gDNA is used as a measure of fungal activity and the storage and loss modulus at different early decay stages are compared against gDNA quantification.

\subsubsection{Genomic DNA extraction}

From each decay duration a $0.4 \mathrm{~g}$ sample of wood was subsampled from the total population $(n=3)$. This sample was then cut to small pieces and then manually ground with a pestle and motar under liquid nitrogen. The samples were then dismembrated for $2 \times 2$ minutes at full speed (with an intermediate liquid nitrogen freezing step) to ensure a consistent powder was achieved (Retsch 300 mill, Retsch GmbH, Haan, Germany). Aliquots of $20 \mathrm{mg}$ were prepared from the powdered material and total gDNA was extracted using DNeasy Plant Kit (Qiagen, Hilden, Germany) which works well for extracting fungal DNA. The manufacturer's protocols were followed. Extractability of gDNA from environmental samples, such as wood, can vary from sample to sample. Hence, to normalise for this potential variation, $0.5 \mathrm{ng}$ of reference DNA pGEM plasmid (pGEM-3Z Vector, Promega, Madison, Wisconsin, USA) was added to each sample at the start of the gDNA isolation (Coyne et al. 2005). The extracted gDNA was eluted in $50 \mu \mathrm{l}$ of buffer $\mathrm{AE}$ and stored in a fridge overnight.

\subsection{2. qPCR anlaysis}

gDNA from $P$. placenta was quantified using quantitative polymerase chain reaction (qPCR) with the ViiA 7 (Applied BioSystems, Forster City, California, USA). A $10 \mu \mathrm{l} \mathrm{PCR}$ reaction using TaqMan $® S Y B R \circledast g r e e n$ mix (Applied Biosystems, Foster City, CA, USA) and $300 \mathrm{nM}$ concentration for the forward primer ACGCCCTGCTCTTCCATTC and reverse primer AAACAGCATCCCCCGTTAGA targeting the $P$. placenta internal transcribed spacer (ITS) gene (GenBank accession EF524035). A $2 \mu$ l template of DNA solution was used both for experimental samples and standard curve. Standard PCR cycling parameters, according to ViiA 7 (Applied BioSystems, Forster City, California, USA), were applied. 
184 Duplicate runs were performed for undiluted, 10- and 100-fold dilutions of all samples. Samples for standard curve was included in each plate.

The internal standard pGEM was quantified in a $10 \mu \mathrm{l}$ PCR reaction with a $300 \mathrm{nM}$ concentration of the forward primer CCCAGTCACGACGTTGTAAAACG, reverse primer TGTGTGGAATTGTGAGC GGA and the FAM-labelled TaqMan®) probe (Applied Biosystems, Foster City, CA, USA) CACTATAGAATACTCAAGCTTGCATGCCTGCA (Coyne et al. 2005) and qPCR was performed on the samples (ViiA 7, Applied BioSystems, Forster City, California, USA).

After amplification the data was analysed and plotted using the ViiA 7 software v1.2.4 (Applied BioSystems, Forster City, California, USA). The extent of amplification was calculated as the mean of 2 replicates from each sample. The yield of P. placenta gDNA was adjusted in relation to the recovery rate of the pGEM reference DNA (Hietala et al. 2014). The same trend was found for undiluted, 10-fold and 100-fold dilutions, but the 100 -fold gave a slightly better yield and is presented in the results chapter.

\subsection{Dynamic Mechanical Analysis}

Dynamic Mechanical Analysis (DMA) was performed on a Triton Technology DMA, using a three point bending mode. The samples were simply supported with a span length of $35 \mathrm{~mm}$. A preload force of $0.6 \mathrm{~N}$ was applied to ensure that the sample remained under loading throughout the oscillation of the applied cyclic force. The amplitude of displacement was $0.05 \mathrm{~mm}$ at a frequency of $1 \mathrm{~Hz}$. This displacement equated to a strain of 0.048 to $0.053 \%$, which is well within the LVR for pine as reported by Sun et al. (2007). The experiment was conducted under isothermal conditions at nominally $25^{\circ} \mathrm{C}$. During the experiments, the temperature showed an increase of no more than $1.0^{\circ} \mathrm{C}$. The isotherm was maintained for 90 minutes.

Samples of $43 \mathrm{~mm}( \pm 2 \mathrm{~mm}$ ) length were cut from the samples exposed to the test fungi as described above. The approximate dimension of cross section was $2 \mathrm{~mm} \times 2 \mathrm{~mm}$, however each was measured using a digital calliper (2 d.p.) after drying prior to loading to the DMA, to ensure precise dimensions were used in the calculation of moduli. The sample was aligned in the machine such that the tangential orientation was parallel to the axis of the applied load. The samples were prepared by drying overnight at $50{ }^{\circ} \mathrm{C}$, and their weight recorded prior to test and at the end of the DMA run. The moisture uptake by the samples over the test duration was noted.

The TTDMA recorded Storage Modulus (E') and Loss Modulus (E") at intervals of $11 \mathrm{~s}$. The $\tan \delta$ value was also calculated as the ratio of Loss Modulus to Storage Modulus. To quantify the mechanical changes, complex modulus ( $\left.\mathrm{E}^{*}\right)$ was chosen as the analysis criterion, where $E^{*}=E^{\prime}+n E^{\prime \prime}$ and $n$ was assumed to be unity.

\section{Results and Discussion}

\subsection{Assessment of early onset decay}

qPCR analysis was used to quantify the presence of P. placenta gDNA within the wood samples. Figure 1 shows the presence of the P. placenta gDNA in the decayed samples, and an increasing trend in the amount of gDNA as the exposure time increases, this is in agreement with the recent work of Ringman et al. (2014) and Alfredsen et al. (2015, 2016). 
Figure 1: Quantity of fungal gDNA isolated (calculated from 100 factor dilution) from wood sample exposed to $P$. placenta for varying time periods

\subsection{Dynamic Mechanical Analysis}

The Dynamic Mechanical Analysis of decay timber has been the subject a very limited studies with only the studies of Birkenshaw et al. (1986) and Monrroy et al. (2011) being prominent within the literature. Further, neither of the two studies deal with initial on-set decay and therefore are not comparable to this study.

A typical DMA output for this isothermal experiment is shown in Figure 2. The control samples, and the majority of decayed samples showed similar behaviour over the 90 minute experimental period. The initial value of $E^{\prime}$ was low, and $E^{\prime}$ increased relatively rapidly over the first few minutes of the experiment. Thereafter the rate of increase slowed and the value tended towards a plateau value, however continuous small upward change was seen throughout the 90 minute period. The increase in E' was accompanied by a decrease in loss modulus (E"), and a corresponding decrease in the $\tan \delta$ value. This behaviour has not been previously reported, but isothermal DMA studies of wood are relatively unexplored. It is suggested that the increase in observed stiffness may be related to changes in dimensions which accompany alteration of moisture content, or to testing outside the linear viscoelastic response region (LVR).

In this study, the moisture content was observed to increase by a small amount during the test period. Values of 1.3 to $3.2 \%$ M.C. were determined at the end of the DMA run. This corresponds with gain of moisture from the atmosphere, and would conventionally be related to a decrease in stiffness (Wilson 1932), rather than the increase observed here. However, moisture content change is likely also to cause small dimensional changes in the cross section of the sample. The change in observed stiffness over time, and any correlation with dimensional change, or effects of moisture sorption within the sample during this period is likely to be complex, and worthy of additional study beyond this present work.

Figure 2. Storage Modulus, Loss Modulus and $\tan \delta$ throughout the isothermal DMA experiment, control sample 3.

Due to the evolution of E' and E" values throughout the test period, data from different time intervals was compared. The average of the initial five data points was calculated as the start value; in addition the value at $60 \mathrm{~s}$ was used, and values at $1000 \mathrm{~s}$, and at 3600 
$\mathrm{s}$ within the plateau region were used. It was found that similar trends occurred in the storage modulus and complex modulus data from the start, middle and plateau stages of the experiment, whereas greater variation was seen in the viscoelastic components (loss modulus and $\tan \delta$ ). This may indicate that further experimentation using temperature scan experiments would provide additional information about changes within the amorphous cellulose and hemicellulose regions of the wood cell wall, relating to viscoelastic response of the material. This will be the subject of further study, however within this paper the elastic component ( $\left.E^{\prime}\right)$ will be considered.

The storage modulus and complex modulus showed similar trends for the samples tested (Figure 3). The values for unexposed control samples had an average value of $1.75 \mathrm{GPa}$ and $1.85 \mathrm{GPa}$ for $\mathrm{E}^{\prime}$ and $\mathrm{E}^{*}$ respectively. No statistically significant difference ( $p=0.05$, by t-test) could be found between this and the 4,8 or 11 day exposure period, however the 4 day exposed samples appeared to gain rather than lose strength. The longest exposure period, 17 days, appeared to lose strength relative to the control and the shorter decay intervals.

[Figure 3a]

[Figure 3b]

Figure 3 (a) Loss Modulus and (b) Complex Modulus for samples exposed to Poria placenta for 0, 4, 8, 11 and 17 days. Average of three samples per exposure period, and error bars represent standard deviation.

Comparison of the change in mean storage modulus at each exposure duration with the mean quantity of fungal gDNA isolated shows a negative correlation between the two variables (Figure $4, \mathrm{R}^{2}=0.9776$ ). While the standard deviation for both P. placenta gDNA and modulus data remains high, this indicates that further study with increased replication may yield further insight into the initial brown rot decay and change in mechanical properties.

Figure 4: Comparison of storage modulus with amount of fungal DNA isolated for the four exposure periods. Error bars represent one standard deviation of the mean.

\section{Conclusion}

The paper reports the effects of initial on-set decay and the presence of fungal DNA within the timber on the storage modulus of the timber. A correlation between observed stiffness and the onset of decay as indicated by the fungal gDNA quantification technique 
has been found. This paper establishes dynamic mechanical analysis as a technique for the assessment of the effects of early on-set decay on the storage modulus of timber.

\section{Acknowledgements}

The authors of the paper would like to acknowledge COST Action FP 1407 for the funding of a Short Term Scientific Mission for Dr. Graham Ormondroyd to visit NIBIO in Norway and also the institute for their very generous hosting throughout his visit, particularly Sigrun Kolstad for her patience in the teaching of new techniques to $\mathrm{Dr}$ Ormondroyd.

Authors Ormondroyd, Curling, Spear and Prabhakaran acknowledge the financial support provided by the Welsh Government and Higher Education Funding Council for Wales through the Sêr Cymru National Research Network for Low Carbon, Energy and Environment.

\section{References}

Alfredsen, G., Pilgård, A., Fossdal, C.G., 2016. Characterisation of Postia placenta colonisation during 36 weeks in acetylated southern yellow pine sapwood at three acetylation levels including genomic DNA and gene expression quantification of the fungus. Holzforschung. DOI: 10.1515/hf-2015-0203.

333 Alfredsen, G., Pilgård, A., 2013. Postia placenta decay of acetic anhydride modified wood - effect of leaching. Wood Material Science \& Engineering 9(3), 162-169.

Alfredsen, G., Ringman, R., Pilgård, A., Fossdal, C.G., 2015. New insight regarding mode of action of brown rot decay of modified wood based on DNA and gene expression studies: A review. International Wood Products Journal 6(1), 5-7.

Arantes, V. Jellison, J. Goodell, B., 2012. Peculiarities of brown-rot fungi and biochemical Fenton reaction with regard to their potential as a model for bioprocessing biomass. Applied Microbiology and Biotechnology 94, 323-338.

Arantes, V., Goodell, B., 2014. Current understanding of brown-rot fungal biodegradation mechanisms: A Review. In: Deterioration and Protection of Sustainable Biomaterials. Eds. Nicholas, D.D., Goodell, B., Schultz, T. ACS Series. Oxford University Press, New York, 344 USA, Vol. 1158, pp. 3-21.

Baldrian, P., Valaskova, V., 2008, Degradation of cellulose by basidiomycetous fungi. FEMS Microbiology Reviews, 32, 501-521.

Becker, H., Noack, D., 1968. Studies on dynamic viscoelasticity of wood. Wood Science and Technology 2:213-230.

349 Birkinshaw, C., Buggy, M., Henn, G.G., 1986. Dynamic mechanical analysis of wood. Journal of Materials Science Letters 5, 898-900.

CEN (1996) EN 113:1996/A1:2004 Wood preservatives - Test method for determining

352 the protective effectiveness against wood destroying basidiomycetes - Determination of the toxic values. CEN (European committee for standardization), Brussels 
Cowling, E.B., 1961. Comparative biochemistry of the decay of sweetgum by white-rot and brown-rot fungi. USDA Technical Bulletin, Washington DC, USA. M.A., Cary, S.C., 2005. Improved quantitative real-time PCR assays for enumeration of harmful algal species in field samples using an exogenous DNA reference standard. Limnology and Oceanography-Methods 3, 381-391.

Curling, S., Clausen, C.A., Winandy, J.E., 2002. Relationships between mechanical properties, weight loss and chemical composition of wood during incipient brown rot decay. Forest Products Journal, 52 (7-8), 34-39.

363 Eikenes, M., Alfredsen, G., Christensen, B.E., Militz, H., Solheim, H., 2005. Comparison of 364 chitosan with different molecular weights as possible wood preservative. Journal of Wood Science 51: 387-394.

Goodell, B., Daniel, G., Jellison, J., Qian, Y., 2006. Iron-reducing capacity of low molecular weight compounds produced in wood by fungi. Holzforschung 60, 630-636.

Goodell, B., Jellison, J., Liu, J., Daniel, G., Paszczynski, A., Fekete, F., Krishnamurthy, S., Jun, L., Xu, G., 1997. Low molecular weight chelators and phenolic compounds isolated from wood decay fungi and their role in the fungal biodegradation of wood. Journal of 371 Biotechnology 52, 133-162.

372 Green, F., Highley, T.L., 1997. Mechanism of brown rot decay: paradigm or paradox. 373 International Biodeterioration \& Biodegradation 39, 113-124.

374 Hietala, A., Stefańczyk, E., Nagy, N.E., Fossdal, C.G., Alfredsen, G., 2014. The suppressive effect of high temperature on wood decay caused by the brown-rot fungus Postia placenta depends on wood durability. Holzforschung 68(1), 123-131.

Hill,, C.A.S., Hale, M.D., Ormondroyd, G.A., Kwon, J.H. Forster, S.C. 2006. Decay resistance of anhydride-modified Corsican pine sapwood exposed to the brown rot fungus Coniophora puteana. Holzforschung 60 625-629

Hillis, W.E., Rozsa, A.N., 1985. High Temperature and chemical affects on wood stability Part 2: The effect of heat on the softening of radiata pine. Wood Science and Technology 382 19, 57-66.

383 Hillis, W.E., Rozsa, A.N., 1978. The softening temperatures of wood. Holzforschung $384 \quad 32: 68-78$.

Jellison, J., Goodall, B., Alfredsen, G., Eastwood, D., Daniel, G., Cragg, S.M., Grace, J.K., 2013. What molecular biology can tell us about the biodegradation of lignocellulose: the utilization of molecular techniques for the detection, identification and enhanced understanding of wood degrading organisms. In: Proceedings of IRG Annual meeting 2013 IRG/WP 13-20528 16-20 June 2013 Stockholm, Sweden.

390 Kelley, S.S., Rials, T.G., Glasser, W.G., 1987. Relaxation behavior of the amorphous 391 components of wood. Journal of Materials Science, 22:617-622.

392 McCarthy, C.J., Birkinshaw, C., Penbroke, J.T., Hale, M., 1991. Dynamic mechanical 393 analysis as a technique for the study of fungal degradation of wood. Biotechnology 394 Techniques 5(6), 493-496. 
395 Monrroy, M., Ortega, I., Ramirez, M., Baeza, J., Freer, J., 2011. Structural change in wood 396 by brown rot fungi and effect on enzymatic hydrolysis. Enzyme and Microbial 397 Technology 49, 472-477.

398 Norimoto, M., Yamada, T., 1966. Dynamic Torsion viscoelasticity of wood. Wood 399 Research 38, 32-39.

400 Olsson, A.-M., Salmén L., 2004. The softening behavior of hemicelluloses related to 401 moisture. In: Hemicellulose: Science and Technology, Eds. Gatenholm, P., Tenkanen, M., 402 American Chemical Society, Washington DC, USA. pp. 184-196.

403 Pilgård, A., Alfredsen, G., Björdal, C.G., Børja, I., Fossdal, C.G., 2011. qPCR as a tool to 404 study basidiomycete colonization in wooden field stakes. Holzforschung 65, 889-895.

405 Ray, M.J., Leak, D.J., Spanu, P.D., Murphy, R.J., 2010. Brown rot fungal early stage decay 406 mechanism as a biological pretreatment for softwood in biofuel production. Biomass 407 and Bioenergy 34, 1257-1262.

408 Ringman, R., Pilgård, A., Richter, K., 2014. Effect of wood modification on gene 409 expression during incipient Postia placenta decay. International Biodeterioration \& 410 Biodegradation 86, 86-91

411 Salmén, L., Olsson, A.-M., 1998. Interactions between hemicellulose, lignin and cellulose: 412 Structure-property relationships. Journal of Pulp and Paper Science 24, 1049-1056.

413 Sun, N. Das, S., Frazier, C.E. (2007) Dynamic mechanical analysis of dry wood: Linear 414 viscoelastic response region and effects of minor moisture changes. Holzforschung 61, 415 28-33.

416 Wilson, T.C.R., 1932. Strength-Moisture Relations for Wood. Technical Bulletin no. 282. 417 United States Department of Agriculture, Washington DC. 88 p.

418 S. L. Zelinka, R. Ringman, A. Pilgård, E. E. Thybring, J. E. Jakes \& K. Richter (2016) The 419 role of chemical transport in the brown-rot decay resistance of modified wood, 420 International Wood Products Journal, 7:2, 66-70 